\title{
Molecular characterization of potential healthcare associated respiratory syncytial virus in three referral hospitals in Kenya, 2009-2011
}

\author{
LM Mayieka ${ }^{\text {* }}$, G Arunga ${ }^{1}$, Z Ng'ang'a ${ }^{2}$, Itromid ${ }^{1}$, S Khamadi ${ }^{3}$, J Oundo ${ }^{4}$, CL Otieno ${ }^{5}$, L Ndegwa ${ }^{6}$ \\ From 3rd International Conference on Prevention and Infection Control (ICPIC 2015) \\ Geneva, Switzerland. 16-19 June 2015
}

\section{Introduction}

Respiratory syncytial virus (RSV) is a major cause of community-acquired severe respiratory illness in infants, immunocompromised individuals and the elderly. Limited information exists on healthcare associated RSV infections in developing countries.

\section{Objectives}

To describe hospital-acquired RSV infections in three Kenyan referral hospitals

\section{Methods}

Ongoing surveillance for healthcare associated infections is conducted at three referral hospitals in Nairobi: Kenyatta National Hospital (KNH), Jaramogi Oginga Odinga Teaching and Referral Hospital (JOOTRH) and Mbagathi District Hospital (MDH). We collected nasopharyngeal and oropharyngeal samples from patients with new-onset fever $\left(\geq 38^{\circ} \mathrm{C}\right)$ and either cough or sore throat, after being afebrile for at least three days in the wards. Specimen were tested for RSV using real time polymerase chain reaction (RT-PCR) and those positive with a cycle threshold value of 30 and below were further grouped as RSV A or B using the same method. The ectodomain of the attachment $G$ glycoprotein was sequenced and phylogenetically analyzed.

\section{Results}

Among 255 cases tested from September, 2009 to September, 2011, 37 (14.5\%) were positive for RSV, including 13 (35\%) subgroup A, 6 (16\%) B, 1 (3\%) mixed AB and $17(46 \%)$ could not be determined. Seventeen

${ }^{1}$ Diagnostics and Laboratory Systems Program, Kenya Medical Research Institute/Centers for Disease Control, Nairobi, Kenya

Full list of author information is available at the end of the article samples were successfully sequenced out of the twenty samples on which this was attempted. Majority of our RSV A isolates belonged to NA1 genotype prototype strain and all RSV B sequences clustered with the BAIV genotype. Three RSV A and 2 RSV B sequences from patients on the same ward at KNH were $100 \%$ identical in the $\mathrm{G}$ ectodomain suggesting potential common source. One RSV A positive specimen from MDH and one from JOOTRH showed 100\% sequence identity.

\section{Conclusion}

Presence of identical sequences indicates potential patient to patient transmission of RSV within the hospitals. Effective and feasible infection control strategies should be enhanced in the Kenyan public hospitals.

\section{Disclosure of interest}

None declared.

\section{Authors' details}

'Diagnostics and Laboratory Systems Program, Kenya Medical Research Institute/Centers for Disease Control, Nairobi, Kenya. ${ }^{2}$ Diagnostics and Laboratory Systems Program, Jomo Kenyatta University of Agriculture and Technology, Nairobi, Kenya. ${ }^{3}$ Henry M Jackson Foundation Medical Research International, USAMRU, Tanzania, United Republic of. ${ }^{4}$ Henry M Jackson Foundation Medical Research International, USAMRU, Kericho, Kenya. ${ }^{5}$ International Emerging Infection Program, KEMRI/CDC, Nairobi, Kenya. ${ }^{6}$ Infection Control Program, kenya Medical Research Institute/Centers for Disease Control, Nairobi, Kenya.

Published: 16 June 2015

\section{doi:10.1186/2047-2994-4-S1-P20}

Cite this article as: Mayieka et al:: Molecular characterization of potential healthcare associated respiratory syncytial virus in three referral hospitals in Kenya, 2009-2011. Antimicrobial Resistance and Infection Control 2015 4(Suppl 1):P20. 